\title{
CARACTERÍSTICAS EPIDEMIOLÓGICAS DAS ANOMALIAS CONGÊNITAS DO TUBO NEURAL EM MENORES DE 5 ANOS DE IDADE E POSSÍVEIS FATORES DE RISCO PARA A SUA OCORRÊNCIA EM CAMPOS DOS GOYTACAZES-RJ
}

\author{
EPIDEMIOLOGICAL CHARACTERISTICS OF CONGENITAL ANOMALIES OF THE NEURAL \\ TUBE UNDER 5 YEARS OF AGE AND POSSIBLE RISK FACTORS FOR THEIR OCCURRENCE \\ IN CAMPOS DOS GOYTACAZES-RJ
}

\author{
CINDY NUNES DA CRUZ ${ }^{1}$, DAMARIS ALBUQUERQUE CARVALHO ${ }^{1}$, JÚLIA MACHADO FERNANDES ${ }^{1}$, MARIANA \\ PIRES SILVEIRA ${ }^{1}$ \\ ${ }^{1}$ Faculdade de Medicina de Campos - FMC
}

RESUMO

As anomalias congênitas, possuem etiologia multifatorial, envolvendo aspectos genéticos e ambientais. Entre diversos fatos geradores, é evidente a importância do ácido fólico na redução ou mesmo prevenção de malformações. Esta vitamina relaciona-se com a síntese de DNA e RNA, portanto, com o desenvolvimento fetal. Foi implementada no País a fortificação compulsória das farinhas de trigo e milho com ferro e ácido fólico resultando em redução de anomalias em 35\%. Enquanto, níveis diários de suplementação medicamentosa superiores a $5 \mathrm{mg}$ de ácido fólico reduz entre $75 \%$ e $91 \%$. Tal fato demonstra a relevância e benefícios do folato no pré-natal. O período ideal de administração seria o periconcepcional, de 1 a 3 meses antes da gestação e até 4 meses após a concepção. Este estudo objetiva avaliar a prevalência de anomalias congênitas do tubo neural de menores de 5 anos de idade no município de Campos dos Goytacazes-RJ, através de um estudo de caso controle para serem analisados possíveis fatores de risco para ocorrência de tais anormalidades. Para análise da distribuição de defeitos do tubo neural com as variáveis: nível socioeconômico e educacional, idade materna, utilização ou não do ácido fólico, realização de pré-natal e número de consultas, rede de atendimento. A amostra coletada é do tipo probabilística aleatória simples, período de realização, 10 de março de 2016 à 30 de maio de 2017. Este projeto atenderá a resolução 196/96 versão 2012 do CNS relativas às questões da ética em pesquisa com humanos.

Palavras-chave: Ácido Fólico. Defeitos do Tubo Neural.
ABSTRACT

Because it is an important cause of childhood morbidity and mortality justifies the analysis of the distribution of neural tube defects in time and space. These birth defects have a multifactorial etiology, involving not only genetic factors but also environmental. It is evident the support and importance of folic acid in reducing or even preventing the occurrence of malformations. That's because this water soluble vitamin is related closely with the synthesis of DNA and RNA and therefore with cell multiplication, which allows its correlation with fetal development and its protective against pediatric cancer. From June 2004 was implemented in the country to mandatory fortification of flour and corn flour with iron and folic acid. However, this resulted in a reduction in the occurrence of anomalies in only $35 \%$. Meanwhile, higher levels of daily supplementation greater than $5 \mathrm{mg}$ of folic acid reduce between $75 \%$ and $91 \%$. This fact demonstrates the relevance and benefits of the implementation of folate prenatal. According to the scientific community, the ideal period for this would be the periconceptional administration, which comprises about 1-3 months before pregnancy and up to four months after conception. This study aims to evaluate the prevalence of congenital neural tube defects in infants under five years old in Campos dos Goytacazes, through a case-control study, so that possible risk factors can be analyzed for the occurrence of such abnormalities in young nurseling in this city. Analyzing the distribution of neural tube defects in time and space according to the following variables will be held: socioeconomic, educational level, maternal age, whether or not the use of folic acid, conducting prenatal, among others. The sample that is collected is the simple probabilistic random, and the period of the study comprised 1st March 2016 until May 30 2017. These project attend the 2012 version of Resolution 196/96 CNS relating to questions of ethics in research involving humans.

Keywords: Folic Acid. Neural Tube Defects. 


\section{INTRODUÇÃO}

O ácido fólico ou folato trata-se de uma vitamina hidrossolúvel de natureza de coenzima e componente do complexo B, cuja fonte é exclusivamente exógena. $O$ folato plasmático encontra-se principalmente sob a forma de tetrahidrofolato, principal forma ativa da vitamina. Sendo assim, é fundamental na síntese de produtos intermediários do metabolismo, o que inclui a formação de purinas e pirimidinas. Estas intimamente se relacionam com a síntese de DNA e RNA e, portanto, com a multiplicação celular; permitindo, então, sua correlação com o desenvolvimento fetal. A deficiência deste nutriente, em seres humanos, apresenta inúmeras causas que incluem: a ingestão inadequada, absorção e metabolismos deficientes e demanda aumentada, principalmente nos períodos de gestação, lactação e crescimento.

Em 2003, a Organização Mundial da Saúde (OMS) publicou o Atlas Mundial de Defeitos Congênitos. Entre os 41 países com dados analisados de 1993 a 1998, o Brasil apareceu em quarto lugar entre aqueles com maior prevalência de anencefalia e espinha bífida, apenas atrás do México, Chile e Paraguai. Segundo a Sociedade Brasileira de Genética Clínica e a Sociedade Brasileira de Genética, aproximadamente $5 \%$ das gestações no Brasil resultam no nascimento de uma criança com algum tipo de anomalia congênita ou doença genética que comprometerá seu desenvolvimento e qualidade de vida. Os gastos com atenção em genética clínica no Sistema Único de Saúde (SUS) tem se mantido na ordem de 49 milhões de reais/ano o que, em média, resulta em $146 \mathrm{mil} /$ dia. Ao passo que a utilização de, por exemplo, $5 \mathrm{mg} /$ dia de ácido fólico o custo envolvido seria de aproximadamente 9 reais a cada 40 comprimidos, indicando, portanto, que o custo benefício da prevenção se sobrepõe, significativamente, aos gastos despendidos com o tratamento.

Por se tratar de importante causa de morbidade e mortalidade infantil, justifica-se a análise da distribuição de defeitos do tubo neural no tempo e no espaço. Isso porque, segundo estudo realizado na Unidade de Medicina Fetal da Maternidade Port Royal - Hospital Cochin em Paris, França, a permanência em berçários costuma ser prolongada e o seguimento contínuo deve se estender por toda a vida do paciente. Cerca de $50 \%$ das crianças afetadas morrem no primeiro ano de vida e as que sobrevivem apresentam incapacidade física e/ou mental importante que requer reabilitação prolongada e de alto custo para a família e sociedade.

Estima-se que em torno de 1-2/1000 nascidos vivos, no Brasil, apresentam defeitos no fechamento do tubo neural, destacando anomalias como a anencefalia, encefalocele e espinha bífida. Essas anomalias possuem etiologia ainda imprecisa. Contudo, é notória sua herança multifatorial, envolvendo não só aspectos genéticos como também ambientais. Os genes atualmente mais estudados no envolvimento dessas anomalias são os pertencentes ao metabolismo do ácido fólico, em especial, o gene da enzima 5,10 metileno-tetra-hidrofolato-redutase. Além da deficiência de ácido fólico, são fatores de risco materno para tais malformações: diabetes melitos, dislipidemia, uso de anticonvulsivantes, de tabaco e doses excessivas de vitamina A $(15,000 / U)$ que alteram o metabolismo do ácido fólico, obesidade materna e hipertermia. Com a introdução do campo 34 na Declaração de Nascido Vivo do Ministério da Saúde, indicador de presença ou não de má formação congênita e/ou anomalia cromossômica tornou-se mais fácil estimar a prevalência de defeitos no tubo neural nos nascimentos no Brasil, mesmo não havendo possibilidade de identificação de defeitos múltiplos ou associados.

É evidente o auxílio e importância do ácido fólico na redução ou mesmo prevenção da ocorrência de malformações. Dessa maneira, é comprovada a associação de seu efeito protetor quanto a neoplasias pediátricas (leucemia, tumores cerebrais e neuroblastoma). No entanto, a complexidade do metabolismo deste nutriente dificulta a plena compreensão de sua participação na embriogênese. Além disso, apesar de evidente necessidade de sua implantação na dieta das gestantes, há discussões na comunidade científica quanto ao seu período de implantação e quantidade a ser administrada. Observou-se que níveis diários de suplementação superiores a $5 \mathrm{mg}$ de ácido fólico reduzem entre $75 \% \mathrm{e}$ 91\% a incidência de defeitos no tubo neural o que depende da concentração sérica basal de folato e da idade das mulheres em estudo. Em contrapartida, uma dosagem de apenas 0,4 a 0,8 mg diários, contribuem com uma redução de apenas $23 \%$ a $66 \%$. Com isso, torna-se indispensável à correlação 
quantidade e efeito protetor da má formação.

Com base no exposto fomentam-se discussões acerca da maneira de administração do nutriente em questão, se através de medicamentos ou suplementação na dieta. Considerando a baixa aderência à suplementação medicamentosa, o governo brasileiro estabeleceu a fortificação compulsória das farinhas de trigo e milho com ferro e ácido fólico, efetivamente implementada no País a partir de junho de 2004, com intuito de diminuir a prevalência de anemia materna e defeitos no tubo neural. Apesar da redução significativa de $35 \%$ com a adesão dessa política no Estado de São Paulo, podem-se obter valores ainda maiores com a utilização de maior quantidade de folato, por exemplo, através da administração medicamentosa. A própria prevalência de seu uso varia amplamente, desde 0,5 a $52 \%$ em estudos realizados em diversos países das Américas, Europa, Austrália e Ásia. Em todos esses, outros determinantes como o nível socioeconômico, educacional, a idade materna, o planejamento, a situação conjugal, a realização de pré-natal e o número de consultas efetuadas bem como a rede de atendimento estão diretamente relacionados com a utilização ou não do ácido fólico.

No Brasil, a utilização de folato apresenta diversos empecilhos: cerca de $50 \%$ das gestações não são planejadas, o que dificulta sua administração no período correto o que, segundo a literatura, seria no período periconcepcional, o que compreende cerca de 1 a 3 meses antes da gestação e até 4 meses após a concepção. Também trata-se de outra dificuldade enfrentada no País a não difusão acerca dos benefícios da utilização de ácido fólico bem como da quantidade e período recomendados. Isso demonstra a necessidade de implantação de políticas públicas voltadas para um amplo espectro que se estende desde um nível teórico até prático. Investindo-se no nível primário, reduz-se, a longo prazo, os gastos com o tratamento de má formações bem como futuros danos emocionais/psicológicos desenvolvidos diretamente com tais dificuldades. Contudo, embora a prevalência de nascidos com anomalias congênitas nos países em desenvolvimento seja similar a dos países desenvolvidos, o impacto na saúde dos portadores desses defeitos é mais alto nos primeiros devido à falta de serviços adequados para o cuidado das crianças afetadas e ao maior índice de exposição para infecções e má nutrição materna. 0 diagnóstico no pré-natal ou no parto permite a intervenção precoce, repercutindo positivamente na qualidade de vida da criança e da família.

Segundo a Organização Mundial da Saúde (OMS) entre os 41 países com dados analisados de 1993 a 1998, o Brasil apareceu em quarto lugar entre àqueles com maior prevalência de anencefalia e espinha bífida. Podendo tal fato estar relacionado ao pouco incentivo das políticas públicas à implementação de ácido fólico nos períodos periconcepcional e gestacional. Isso reflete no alto gasto do Sistema Único de Saúde para assistência deste paciente, cerca de 49 milhões de reais/ano. Portanto, demonstra-se a necessidade de medidas preventivas em contrapartida ao tratamento, o que é explicitado nesta pesquisa.

Este estudo objetiva avaliar a prevalência de anomalias congênitas do tubo neural em menores de 5 anos de idade no município de Campos dos Goytacazes-RJ, através de um estudo de caso controle, para que possam ser analisados possíveis fatores de risco para a ocorrência de tais anormalidades nesse grupo de crianças desta cidade. Espera-se que com este trabalho possam ser conhecidos os reais fatores associados à ocorrência destas alterações para que sejam programadas ações preventivas e de melhorias na assistência do PréNatal.

\section{MÉTODOS}

O presente estudo é epidemiológico observacional, longitudinal e analítico. Foram selecionados 218 nascidos vivos menores de 5 anos de idade, em Unidades de Saúde no município de Campos dos Goytacazes-RJ, no período de março de 2016 a maio de 2017. A partir da triagem de um grupo caso contendo 18 crianças com anomalias congênitas do tudo neural bem como um grupo controle de 200 com características similares, mas sem qualquer anomalia neurológica.

A amostra é do tipo probabilística aleatória simples na qual todos os membros têm chances equivalentes de serem selecionados. Obtida a partir de consulta aos hospitais: Hospital dos Plantadores de Cana (HPC) localizado na Avenida José Alves de Azevedo, 337-Parque Rosário e Hospital Sociedade Portuguesa de Beneficência de Campos em Rua Barão de Miracema, 142-Centro. Sendo todos estes localizados no município de Campos dos GoytacazesRJ. 
As variáveis coletadas foram: a cor, o número de gestações, a incidência de malformação, o auxílio paterno, o planejamento da gestação, a realização de pré-natal assim como o número de consultas, rede de atendimento, os hábitos alimentares, uso de medicação contendo ácido fólico, sua quantidade, o período utilizado e o conhecimento acerca de sua utilização, vícios, dados socioeconômicos e, por fim, as patologias associadas. Os critérios de exclusão basearam-se em: não ter nascido em Campos dos Goytacazes, ter o responsável se recusado a assinar o Termo de Consentimento Livre e Esclarecido, ser maior de cinco anos de idade na época do estudo bem como ser analfabeto.

Este projeto não representou nenhum risco ao sujeito de pesquisa e possuiu como benefícios: o conhecimento dos reais fatores associados à ocorrência das anomalias congênitas do tudo neural visando à prevenção e a melhoria na assistência do Pré-Natal.

O mesmo foi encaminhado para apreciação e aprovação pelo Comitê de Ética em Pesquisa sendo aprovado em 15 de novembro de 2015, sendo possível então, o início das atividades.

A coleta de dados foi realizada pela técnica do questionário de múltipla escolha com opção de resposta. Antes deste processo todos os envolvidos foram devidamente esclarecidos dos objetivos da pesquisa bem como de sua contribuição para com a sociedade.

Os dados obtidos foram tabulados com a ajuda do programa EPIDATA 3.1 e randomizados de acordo com a ferramenta de randomização do Microsoft Excel ${ }^{\circledR}$.

\section{RESULTADOS}

A partir dos dados obtidos observamos a importância da suplementação medicamentosa, visto que a ingesta alimentar, apesar de primordial, foi insuficiente na prevenção de ocorrência de malformações. Assim sendo, obtemos os seguintes resultados: dentre as pacientes que consumiram feijão, ovo, verduras verde escuras, leveduras ou fígado, três ou mais vezes na semana, $91 \%$ das crianças não apresentaram anomalias congênitas (Figura 1). Resultado semelhante foi obtido comparando o consumo de farinha de trigo ou milho com a ocorrência de tais desordens genéticas (Figura 2). Dessa forma, mesmo que insuficiente, a ingesta
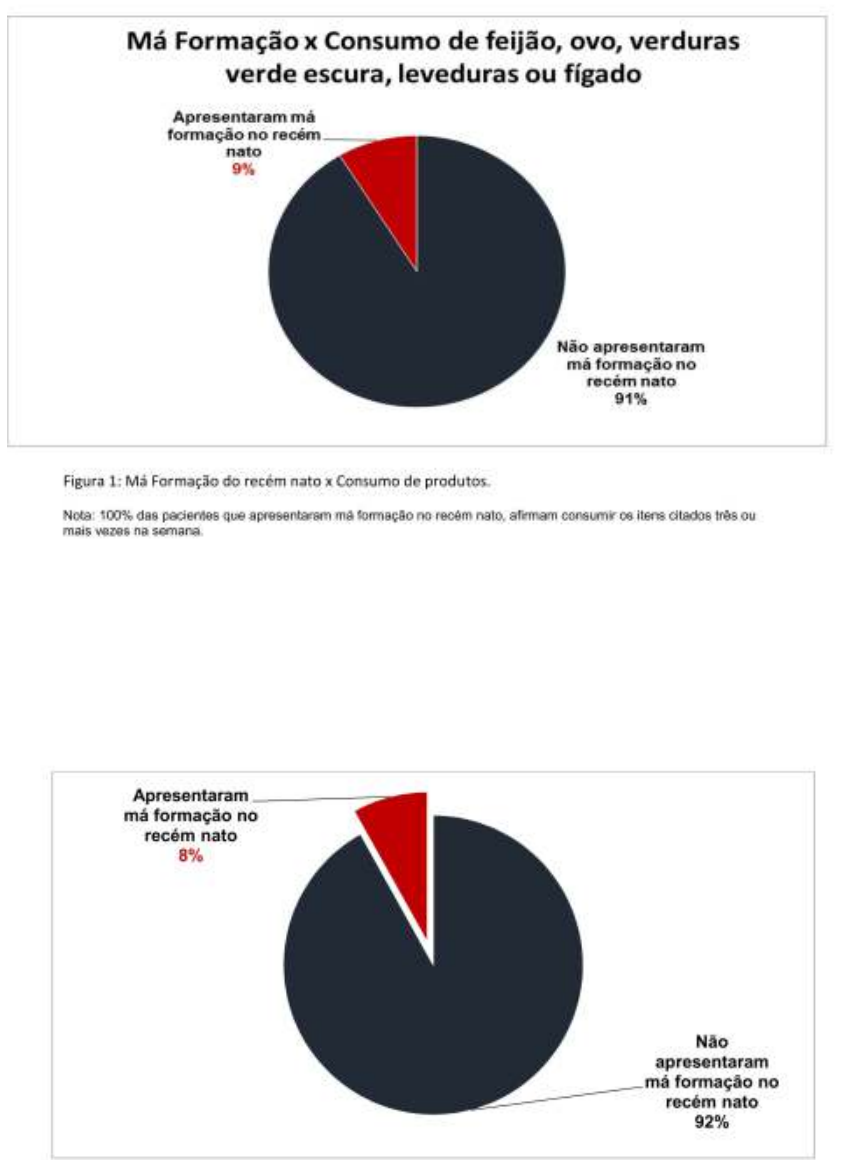

Figura 2: Má Formação $\times$ Consumo de farinha de trigo ou milho.

alimentar mostrou-se como um importante fator protetor, ratificando a necessidade de uma associação: dieta e suplementação medicamentosa, a fim de uma efetiva redução de casos.

Quanto à suplementação medicamentosa, é evidente sua necessidade e importância, sendo corroborada a partir da seguinte dicotomia: dose utilizada bem como seu período de utilização. Com relação a dose utilizada, houve no estudo uma dificuldade na obtenção da posologia do mesmo, uma vez que, com frequência, esses dados não eram acessíveis e, portanto, sujeitos ao esquecimento da entrevistada. Por outro lado, com relação ao período recomendado, o presente estudo em consonância com a literatura internacional, demonstrou que a suplementação de ácido fólico no período periconcepcional até a 12a semana de gestação pode prevenir o Defeito do Tubo Neural no Feto, assim, constatamos que apenas $2 \%$ das gestantes cuja suplementação foi iniciada dois a três meses antes da 
concepção apresentou malformação na prole (Figura 3). No entanto, notamos o quão subestimada é essa informação, uma vez que carecem de divulgação apropriada, não sendo realidade no Brasil tampouco no município de Campos dos Goytacazes sua utilização no período recomendado.

Tendo em vista tratar-se de uma anomalia cuja influência é multifatorial, outros dados foram analisados, a saber: realização e frequência de prénatal, hábitos de vida além de grau de instrução materna. Quanto ao pré-natal, observou-se que não só sua realização como também o número de consultas foi determinante no efeito protetor das anomalias congênitas, uma vez que $86 \%$ das pacientes que fizeram tal acompanhamento apresentaram recém-natos saudáveis (Figura 4). Dentre esses, $51 \%$ das progenitoras realizaram 7 ou mais consultas (Figura 5).

Já em relação aos hábitos de vida observouse, no estudo, resultados destoantes da realidade brasileira, uma vez que o etilismo e o tabagismo não demonstraram nexo causal com o diagnóstico analisado (Figuras 6 e 7). Acredita-se que o método baseado na realização de entrevista possa ter interferido nos resultados obtidos de forma a mascarar o quociente. No que diz respeito ao grau de instrução materna, a maior escolaridade representou um amplo acesso a informação, gerando, consequentemente, maior adesão ao tratamento vigente, já que não houve casos relatados em filhos de gestantes com ensino superior completo e mesmo para aquelas com ensino superior incompleto esse número foi ínfimo. (Figura 8).

A partir da análise estatística dos dados, comprovou-se a real importância da suplementação exógena na prevenção das anomalias congênitas, uma vez que $90 \%$ das pacientes que usaram ácido fólico apresentaram recém-nato saudável (Figura 9). Dessa forma, a associação dieta versus suplementação medicamentosa se mostrou primordial na prevenção de tal distúrbio congênito.

\section{CONSIDERAÇÕES FINAIS}

As anomalias congênitas, fruto de defeitos do tubo neural possuem etiologia multifatorial, envolvendo não só aspectos genéticos como também ambientais. Entre diversos fatores geradores, é evidente o auxílio e importância do ácido fólico na redução ou mesmo prevenção da

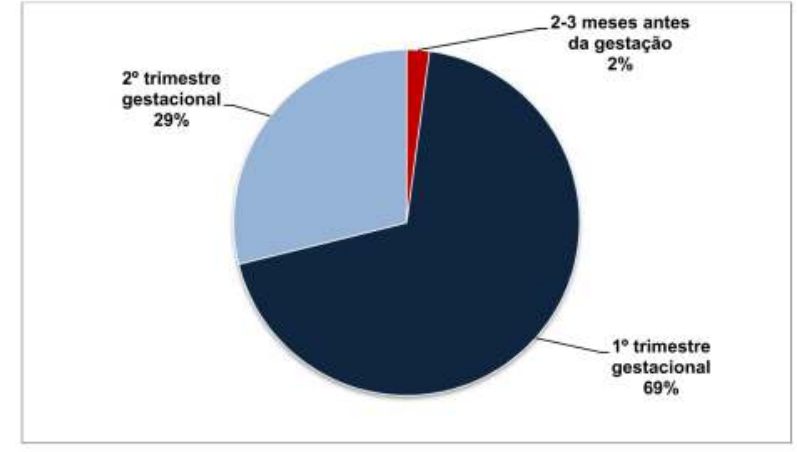

Figura 3: Ausência de Má Formação x Periodo de Utilizaçăo

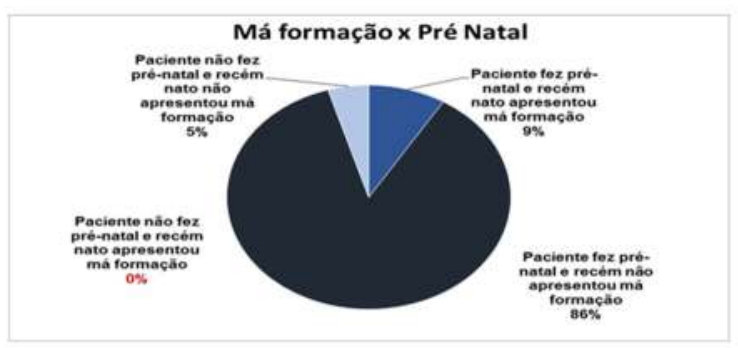

Figura 4: Mà formaçẫo x Pré Natal

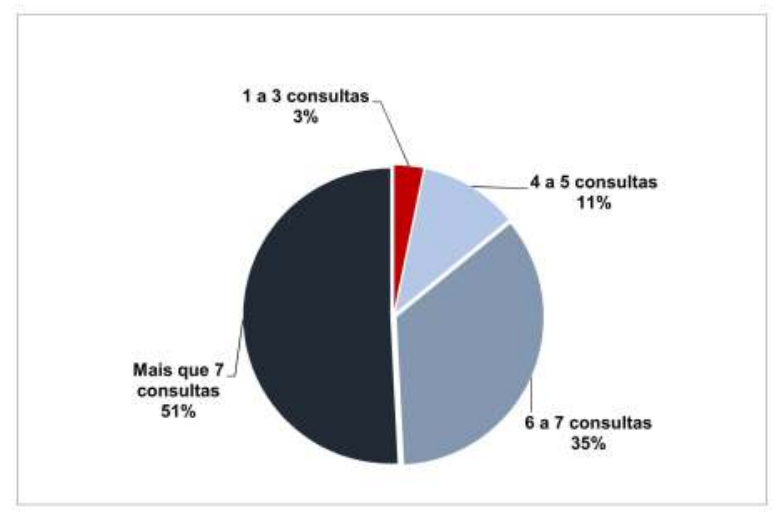

Figura 5: Ausència de Má formação x Frequência Pré Natal

Má formação x Uso de Bebidas Alcoólicas

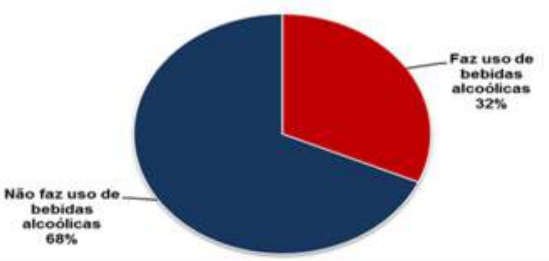

Figura 6: Má Formaçāo x Uso de Bebidas Alccólicas.

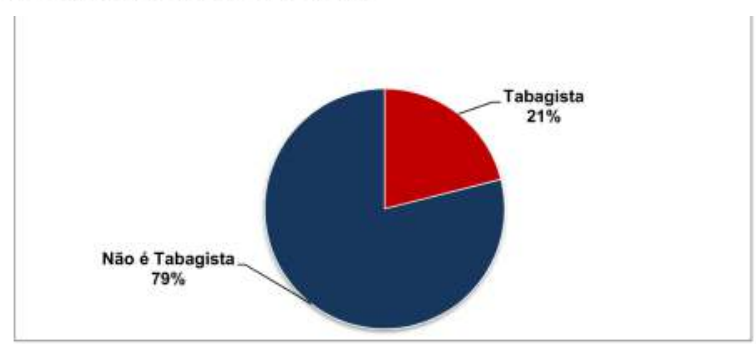

Figura 7: Má formação x Tabagismo. 


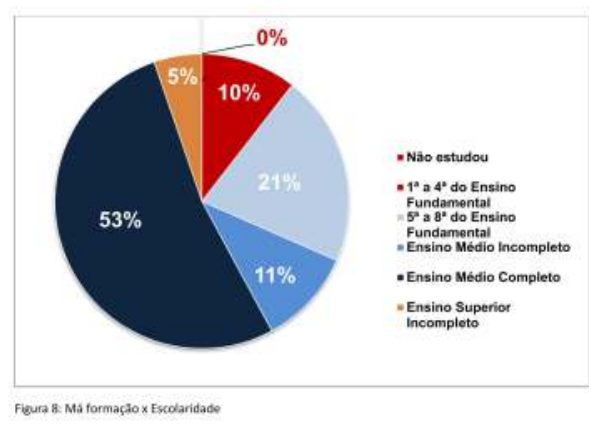

ocorrência de malformações.

Então: qual seria a causa essencial das malformações congênitas? Observamos no transcorrer do estudo, um desconhecimento das entrevistadas no que se refere a importância do ácido fólico bem como o período recomendado para sua utilização. No entanto, o conhecimento atual nos faz concluir que isso advém de uma desinformação prévia, isto é, não foi repassado tal informação, logo, o erro estaria na relação médico versus paciente? E/ou seria isso uma negligência governamental? Constatamos que em nenhum momento da vida da mulher ou de seu pré-natal houve um projeto social que esclarecesse as mesmas quanto a importância desse mineral. Torna-se então evidente a necessidade de fomentar não apenas novas medidas públicas como também uma relação médico paciente holística - que avalie a gestante integralmente, garantindo a adesão desta ao prénatal e, portanto, um sucesso de suas medidas.

A partir de junho de 2004, foi implementada no país a fortificação compulsória das farinhas de trigo e milho com ferro e folato. No entanto, tal medida foi insuficiente na região estudada, uma vez que dentre as pacientes que consumiram feijão, ovo, verduras verde escuras, leveduras ou fígado, 3 ou mais vezes na semana, $9 \%$ das crianças apresentaram anomalias congênitas. Comparativamente $90 \%$ das gestantes que

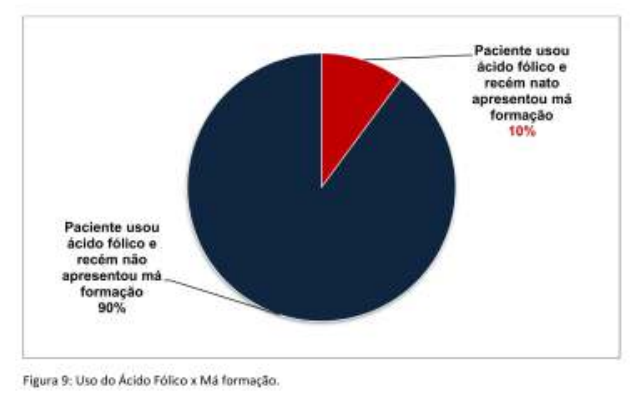

utilizaram a suplementação medicamentosa apresentaram recém-nato saudável, ratificando a necessidade de uma associação: dieta e medicamento, a fim de uma efetiva redução de casos.

Ainda há muito a ser esclarecido acerca do ácido fólico, suas vias de metabolismo e participação na embriogênese, os quais pelo conhecimento atual carecem de maior e melhor elucidação. A partir dos dados do estudo e em comparativo com a literatura internacional é evidente o nexo causal ácido fólico e anomalias congênitas do tubo neural. No entanto, existem uma série de covariáveis associadas a esse resultado, ratificando o aspecto multifatorial da desordem em questão. Faz-se necessário, assim, o incentivo a novas pesquisas na área que possam esclarecer a contribuição desse cofator não só no Norte-Fluminense como em outras regiões brasileiras uma vez que a realidade socioeconômica e o acesso à informação são um aspecto chave no resultado final.

A partir da interpretação gerada pela análise dos dados, podemos concluir o quão essencial e fundamental é a Pesquisa não apenas estatisticamente, mas principalmente socialmente. Demonstrando assim, uma necessidade quanto a um investimento na atenção primária de forma a reduzir gastos bem como propiciar uma melhor qualidade de vida a essa futura geração.

\section{REFERÊNCIAS}

Almeida LC, Cardoso MA. Recommendations for folate intake in women: implications for public health strategies. Cad. Saúde Pública vol.26 no.11 Rio de Janeiro Nov. 2010.

Barbosa Lorena, Ribeiro Davianne de Queiroz, Faria Flávio Cunha de, Nobre Luciana Neri, Lessa Angelina do Carmo. Fatores associados ao uso de suplemento de ácido fólico durante a gestação. Rev. Bras. Ginecol. Obstet. [serial on the Internet]. 2011 Sep [cited 2014 Aug 10];33(9):246-251;. 
Bortolus R, Blom F, Filippini F, van Poppel MN, Leoncini E, de Smit DJ, Benetollo PP, Cornel MC, de Walle HE, Mastroiacovo P; Italian and Dutch folic acid trial study groups. BMC Pregnancy Childbirth. 2014 May 13;14:166. doi: 10.1186/1471-2393-14-166.

Fonseca Vania Matos, Sichieri Rosely, Basilio Luciana, Ribeiro Luciana Viana da Costa. Consumo de folato em gestantes de um hospital público do Rio de Janeiro. Rev. bras. epidemiol. [serial on the Internet]. 2003 Dec [cited 2014 Aug 10] ; 6( 4 ):319-327;

Fujimori Elizabeth, Baldino Camila Florido, Sato Ana Paula Sayuri, Borges Ana Luiza Vilela, Gomes Murilo Novaes. Prevalência e distribuição espacial de defeitos do tubo neural no Estado de São Paulo, Brasil, antes e após a fortificação de farinhas com ácido fólico. Cad. Saúde Pública [serial on the Internet]. 2013 Jan [cited 2014 Aug 10] ; 29(1): 145-154;

Pacheco Sâmya Silva, Braga Cynthia, Souza Ariani Impieri de, Figueiroa José Natal. Efeito da fortificação alimentar com ácido fólico na prevalência de defeitos do tubo neural. Rev. Saúde Pública [serial on the Internet]. 2009 Aug [cited 2014 Aug 10]; 43(4): 565-571;

Romero Muñoz Daniel. Quem deve cuidar da capacitação dos membros dos comitês de ética?. Rev. Assoc. Med. Bras. [serial on the Internet]. 2004 Dec [cited 2014 Aug 10] ; 50( 4 ): 357-357. 